\title{
MÚSICA QUE HACE CINE: EL COMPOSITOR ZBIGNIEW PREISNER*
}

\section{MUSIC WHICH CREATES CINEMA: THE COMPOSER ZBIGNIEW PREISNER}

Ana Mainer Martín

Conservatorio Superior de Música de Aragón (CSMA)

\section{Resumen:}

En este trabajo nos proponemos reflexionar sobre la relación entre música y cine a través del análisis de la trilogía cinematográfica Tres colores (Trois Couleurs) del realizador Krzysztof Kieslowski y del compositor Zbigniew Preisner. Tras su análisis concluimos que, en casos como el que nos ocupa, la fusión y entendimiento entre ambos campos artísticos, preservando su autonomía, alcanza cotas ciertamente relevantes y subyugantes. En todo caso, destacamos que cuando este género musical adquiere entidad per se, puede llegar a producir auténticas obras maestras.

\begin{abstract}
:
This paper aims to reflect on the relationship between music and cinema through the analysis of the film trilogy Three Colors (Trois Couleurs) by the filmmaker Krzysztof Kieslowski and the composer Zbigniew Preisner. After analysis we conclude that, in cases like the present one, fusion and understanding between the two fields of art, preserving their autonomy, reaches heights certainly relevant and captivating. In any case, we note that when this genre acquired entity per se, can produce masterpieces
\end{abstract}

Palabras clave: Música en el cine; bandas sonoras; compositores cinematográficos; Zbigniew Preisner; Krzysztof Kieslowski; la Trilogía de los Tres Colores.

Keywords: Film music; soundtracks; film composers; Zbigniew Preisner; Krzysztof Kieslowski; the Three Colors Trilogy.

\footnotetext{
* Este artículo ha sido elaborado a partir del Trabajo de Investigación de Fin de Licenciatura de la autora en el curso 2011-2012 en el Conservatorio de Música de Aragón (CSMA)
} 


\section{Introducción}

La expresión música que hace cine resulta evidente en el caso del cine musical, pero posiblemente pueda no parecerlo tanto en otros géneros cinematográficos.

Desde que la música de cine viera la luz, desde los comienzos de este arte, se la ha venido considerando menos importante que otras. Sólo podía aspirar a acompañar las imágenes, a redondear el resultado final de la película, y por supuesto, a no interceptar el mensaje visual en demasía. A esta subordinación del sonido a la imagen se ha de añadir necesariamente que son pocos los compositores que se han dedicado a este género en exclusividad. Sin embargo, sí hay muchos que han compatibilizado y compatibilizan el trabajo para el cine con la creación musical independiente. De hecho, son a menudo estos compositores de cine ocasionales, como es el caso de Bernard Herrmann, muy conocido precisamente por sus numerosas y geniales bandas sonoras, los que más han contribuido a reforzar la idea de que se trata de un género musical menos serio que otros y que sirve principalmente para proporcionar una notoriedad fácil al compositor.

'Bernard Herrmann once remarked: The twenty-first century won't be interested in our painting, our literature or our architecture so much as in our motion pictures, because the motion picture is the first truly original art form of the twentieth century. Real composers welcome any opportunity to write music and any composer who disdains writing music for films, radio or television, or any other medium, is doomed to oblivion'. (Johnson, 1977)

Son muy pocos los compositores que, como el polaco Zbigniew Preisner, creen verdaderamente que la música de cine tiene existencia y entidad propias, más allá de la imagen y la trama argumental, y menos aún los que han encontrado en el cine su principal fuente de inspiración. Su música, muy rica y peculiar, cumple al mismo tiempo tanto con los requisitos del contrato audiovisual, como con los de su exigente creador. 
Intentaremos mostrar, a través del análisis de la trilogía citada, la relación entre el texto fílmico y la música, que, más allá del extraordinario entendimiento entre ambos creadores, la música que el compositor polaco ideó tiene su propia autonomía. A tal efecto hemos seguido un doble análisis de la obra cinematográfica (guión, discursividad, estética, etc.) y de la musical, centrándonos en el proceso de diálogo que posibilitó una extraordinaria interdependencia entre campos artísticos así como, especialmente, en el trabajo seguido por Preisner para construir lo que consideramos una obra maestra.

\section{2.- Marco teórico y metodológico: el encuentro de dos grandes creadores}

“(...) Seguir a un personaje principal, entrar en su psicología. Todo ello, cosas que me han sido útiles para componer música de películas. Comprendí que la música podía convertirse en actor y trabajar sobre nuestro inconsciente" (Montalt, 2003, 55).

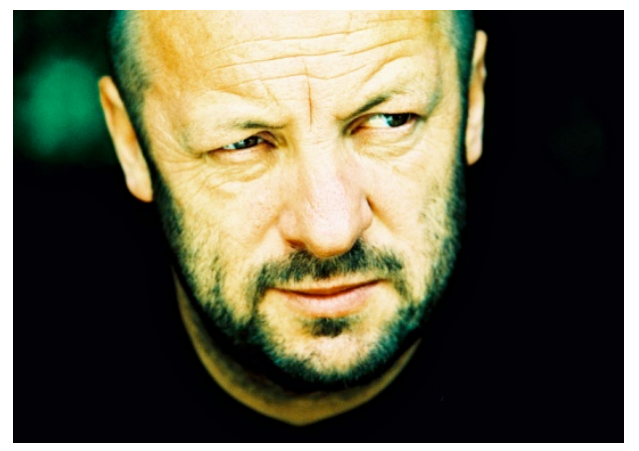

F 1. El compositor Zbigniew Preisner

Preisner se sintió muy pronto identificado con el movimiento Moral concern de la filmografía polaca de los años setenta y ochenta. En este contexto artístico, Preisner conoció al realizador Krzysztof Kieslowski y a su guionista y amigo Krzysztof Piesiewicz.

Kieslowski siempre trata en su cine los grandes temas que a todos los seres humanos nos preocupan: el amor, la muerte, los conflictos y dilemas morales que se nos plantean, nuestros referentes éticos, azar vs destino, etc. La mayor parte de los artistas han reflexionado acerca de ellos. Sin embargo, lo que 
hace a Kieslowski especial es su estrecha relación con el género documental, muy próximo de la realidad, y su manera de comunicarse con el espectador, planteándole un espacio para la reflexión pero sin proponer respuestas concretas a dichas cuestiones y, sobre todo, contando con su inteligencia y sensibilidad.

La trama argumental de sus películas suele ser aparentemente sencilla y sus protagonistas son también gente corriente con la que muy a menudo puede identificarse el espectador. Sin embargo, si observamos detenidamente estas historias, descubrimos un sinfín de detalles que las convierten en verdaderas obras maestras de una gran belleza estética. El trabajo de Kieslowski es minucioso; ningún detalle es dejado al azar y todo (reparto, fotografía, música, vestuario, maquillaje...) está sumamente medido y cuidado.
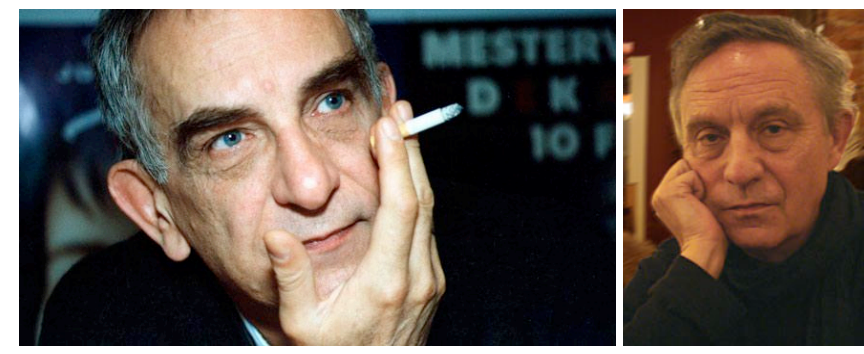

F 2 y 3. El realizador Krzysztof Kieslowski y el guionista Krzysztof Piesiewicz

Durante muchos años Preisner mantuvo una estrecha relación personal y profesional con Krzysztof Kieslowski y Krzysztof Piesiewicz. Sus partituras para las películas de Kieslowski, como Dekalog (1988), La doble vida de Verónica (La double vie de Véronique, 1991), La trilogía de los Tres Colores (Trois couleurs: Bleu, Trois couleurs: Blanc, Trois couleurs: Rouge, 19931994) le han hecho merecedor del elogio y reconocimiento internacionales. $\mathrm{Su}$ obra Requiem for my friend (Requiem Dla Mojengo Przyjaciela, 1998), dedicada al realizador Krzysztof Kieslowski, fallecido en 1996, deja testimonio del profundo impacto personal y artístico que dejó el cineasta en el compositor.

En la película que nos ocupa, La trilogía de los Tres Colores, Kieslowski se propone examinar la vigencia de los tres ideales de la Revolución Francesa (libertad-igualdad-fraternidad), observando cómo influyen en la vida 
cotidiana de individuos concretos. Así Trois couleurs: Bleu corresponde a la libertad, Trois couleurs: Blanc a la igualdad y Trois couleurs: Rouge a la fraternidad. Por otra parte, la Trilogía es la última obra del cineasta polaco, fallecido repentinamente, de modo que toda ella, y muy especialmente su tercera parte, ha adquirido una inesperada dimensión testamentaria.

\section{3.- Exposición: poniendo música a la poesía}

Hasta aquí podemos deducir que el cine de Kieslowski es una compleja combinación de cotidianeidad, abstracción y fuerte mensaje moralizante. Y precisamente la intangibilidad y la abstracción que domina en sus producciones cinematográficas se adaptan muy bien a la música. Krzysztof Piesiewicz, ha destacado, con razón, que en su cine, más que contar historias, describían personajes (Montalt, 2003, 52). Este dato es fundamental para comprender el papel de la música de Preisner que muy bien podría considerarse un personaje más de sus películas. Lo mismo podría afirmarse acerca de la extraordinaria fuerza protagónica que adquieren los objetos (una moneda en Trois couleurs: Blanc, una pequeña pelota de goma en La double vie de Véronique, una medalla en Trois couleurs: Bleu...), transmutados en personajes en el simbólico mundo creado por este cineasta.

Krzysztof Kieslowski, en una entrevista concedida en 1993, declaró: "No sé nada de música. Tengo clara la atmósfera que quiero en mis películas; pero no sé qué tipo de música podría proporcionármela, ni sabría cómo escribirla. Preisner es la persona adecuada con la que puedo colaborar" (Montalt, 2003, 54-55). De hecho, en sus primeras películas había recurrido a temas preexistentes y trabajó con otros compositores antes de coincidir con Zbigniew Preisner, pero pronto comprendió, como comentó el propio Presiner, que la música podía aportar a una película algo que no podía proporcionar la imagen y viceversa: “(...) combinando imagen y música, repentinamente nace un significado, un cierto valor, algo que llega a determinar una atmósfera." (Montalt, 2003, 55). 
En 1993, a propósito del resultado de la primera parte de la trilogía, Trois couleurs: Bleu, Kieslowski comentó que quizás se debería añadir a Zbignew Preisner como colaborador del guión. La implicación de Preisner en el trabajo en equipo que desarrolló con Piesiewicz y Kieslowski permitió que el compositor conociera prematuramente el guión de dos de las partes de la Trilogía, Trois couleurs: Bleu y Trois couleurs: Rouge, lo cual le permitió componer la banda sonora anticipadamente. Un trabajo maduro y concienzudo que muchos compositores de cine no pueden desarrollar, al tener que escribir su música rápidamente, a menudo ya en la fase de montaje de la producción fílmica.

Kieslowski daba mucha libertad a Preisner. En el guión de la Trilogía ya se especificaba la duración precisa de la música en la escena, pero, tal vez precisamente por no ser músico, Kieslowski dejaba a Preisner componer la música que quisiera y también elegir los músicos que debían interpretarla.

\section{1.- El magnetismo de la música de Preisner}

Preisner no concibe grandes diferencias entre el género cinematográfico y la música independiente. Define su música como creativa (Ponti, 1998) en el sentido general del término y, precisamente, parte de la singularidad de sus obras se encuentra en esta concepción ambigua: su música de cine no cae en los abundantes tópicos hollywoodienses ${ }^{1}$ y sus creaciones independientes, como el Réquiem (1998), poseen una peculiar influencia cinematográfica.

Por otra parte, el compositor incide en la idea de que compone lo que a él le gustaría escuchar. Creemos que ésta es la más importante ambición de todo artista, conseguir crear algo que de verdad le satisfaga personalmente: “(...) I compose such music that I would like to listen to, if it weren't me who composed it. And I must advise myself with my own taste. I must trust it. As for the time being, I think I don't err in what I'm doing; I don't err in my

\footnotetext{
${ }^{1}$ Véase, por ejemplo, la banda sonora de la última película de la saga Star Trek (J.J. Abrams, 2013), en la que abundan los efectos de sonido, los bruscos cambios de tempo y ritmo y el empleo de una orquestación con gran presencia del viento metal. Consideramos que, la mayor parte de las veces, este tipo de música no es susceptible de ser escuchada sin los efectos visuales de los que ésta forma parte.
} 
taste.” (Ponti, 1998). Las características y particularidades compositivas del músico polaco son fácilmente discernibles en toda su obra y están muy presentes en la que aquí nos ocupa, la citada Trilogía de los Tres Colores: el uso de una tonalidad misteriosa, su carácter austero, su identidad como compositor, etc. Son aspectos que analizaremos a continuación.

Zbigniew Preisner define su estilo como una especie de nuevo romanticismo. $\mathrm{Y}$ es cierto que su música está basada en el sistema tonal, aunque con frecuencia la presencia de determinadas alteraciones y cromatismos en las melodías puedan llegar a enturbiar considerablemente dicha tonalidad. Estas notas extrañas confieren a la música de Preisner un matiz muy misterioso y singular, muy en consonancia con los dilemas existenciales que plantea la filmografía de Kieslowski. Los personajes y las historias de Kieslowski, aunque aparentemente sencillas, encierran una gran complejidad. En muchas ocasiones los diálogos no abundan y es la música la encargada de describir el estado de ánimo de los protagonistas, hecho que en la película Trois couleurs: Bleu alcanza su máxima significado.

Paradójicamente, muy a menudo Preisner huye de artificios orquestales en sus composiciones y crea pequeñas melodías; dichas melodías suelen ser simples en cuanto a material sonoro y, en su mayoría, están plagadas de pausas, silencios que se van intercalando y cortando la frase en motivos cortos, resultando un conjunto en extremo austero. Sin embargo, con ellas consigue transmitir una gran profundidad emocional. Son interpretadas por determinados instrumentos, explotando sus particularidades tímbricas. Así, emplea la flauta dulce, a menudo utilizando muy destacadamente el recurso expresivo del vibrato. Con asiduidad, muestra preferencia por instrumentos de viento madera para los solos (flauta, clarinete, oboe o corno), pero también elige otros de otras familias, como el violín, el piano, el arpa, y la voz soprano. El tejido orquestal, si existe, se reduce muchas veces a notas tenidas, a veces al margen de dichas melodías. Desde el punto de vista del tópico cinematográfico, un dato muy destacable es ausencia casi total de la familia del viento metal en su música (a excepción del saxofón solista) y de la percusión. Pero Preisner es, sin duda, un compositor complejo que precisa de 
otras identidades, a modo de heterónimos, para desplegar su creatividad. Veámoslo.

Desde la novena parte de Dekalog (Krzystof Kieslowski, 1988), el compositor Van den Budenmayer aparece de manera recurrente en cada una de las tramas argumentales de las películas de Kieslowski. Incluso se le atribuyen algunos temas musicales de diversas películas, entre ellas La Trilogía de los Tres Colores, también en las grabaciones discográficas. Se le identifica como un compositor de origen holandés que vivió entre 1752 y 1793, cuyo imponente estilo compositivo es, supuestamente, muy diferente al de Preisner, agudizando un atractivo contraste musical al convivir sus composiciones en la misma película.

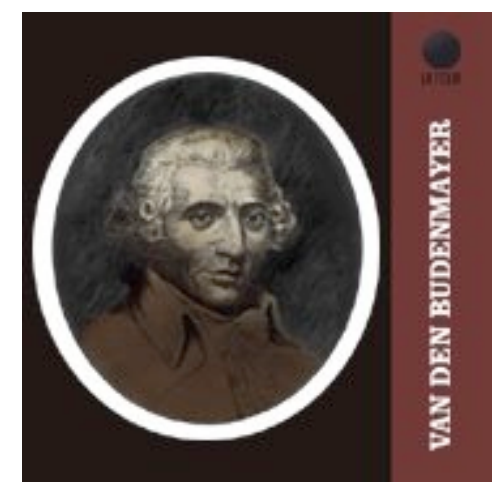

F 4. El misterioso compositor Van den Budenmayer

La música de Budenmayer se apoya sobre una gran orquesta (también, ocasionalmente, coros y órgano) a menudo coronados por una voz de soprano como solista. A diferencia de Preisner, Budenmayer emplea el viento metal, en especial la trompeta solista, y una gran cantidad de instrumentos de percusión variada (especialmente importante es el uso de campanas tubulares y timbales, pero también gong, caja, bombo, carillón y xilófono) que refuerzan el dramatismo de su música.

¿Por qué recurre Kieslowski a este otro compositor? En ocasiones muy determinadas, que veremos posteriormente en el análisis de la Trilogía, Kieslowski requiere una gran intensidad emocional, muy especialmente en lo que respecta a la música, parte principal de la trama en la mayoría de sus películas. Es aquí donde Preisner muestra toda su capacidad musical, 
convirtiéndose en otro compositor, que se nos da a conocer como Van den Budenmayer, y desplegando un estilo compositivo totalmente atípico, intenso e inconfundible. Podemos disfrutarlo tanto en películas, por ejemplo en el "Concierto en E minor" de La doublé vie de Véronique (Krzysztof Kieslowski, 1991) o el "Concierto para la Unificación de Europa" de Trois couleurs: Bleu (Krzysztof Kieslowski, 1993), como en música independiente, por ejemplo el inolvidable "Lacrimosa" de Réquiem for my friend, 1998.

Van den Budenmayer es pura ficción, una figura inventada entre Kieslowski y Preisner que permitió al segundo desplegar la figura del compositor clásico que necesitaba en Dekalog. La broma se mantuvo en posteriores colaboraciones, permitiendo al realizador volver a este estilo más clásico de música de concierto, siempre que lo requiriese la trama y, al mismo tiempo, permitiendo a Preisner, a través de su alter ego, formar parte esencial como personaje al que se hace referencia en las películas. Por otra parte, desde un punto de vista formal, Budenmayer otorga unidad a toda la filmografía de Kieslowski desde su primera aparición en Dekalog hasta la última en Trois couleurs: Rouge; la que fuera también la última película del realizador polaco.

La ficción resultó tan creíble, que todos los melómanos se lanzaron a la búsqueda del misterioso compositor holandés. Años después, la prestigiosa editorial Oxford University Press se interesó por tan brillante compositor del siglo XVIII, pidiendo a Kieslowski toda la información posible para incluirla en la "Enciclopedia Universal de la Música". Cuando el director contestó que la música había sido escrita por un compositor actual polaco, los británicos le reprocharon haber sido poco serio ocultando información.

Finalmente, por lo que a interpretación se refiere, un dato a tener en cuenta es que Zbignew Preisner también es extremadamente cuidadoso a la hora de seleccionar a sus músicos: suele trabajar siempre con los mismos solistas, lo cual confiere a su obra mayor unidad si cabe. Sabedor del gran potencial de la soprano Elzbieta Towarnicka, ha compuesto para ella buena parte de sus temas firmados por Budenmayer, cuya extraordinaria voz está indisolublemente asociada a estas piezas. También el saxofonista Jerzy 272 
Glowczewski, el violinista Wieslaw Kwasny, el pianista Konrad Mastylo, o el flautista Jacek Ostaszewski se repiten en muchas de sus películas y grabaciones discográficas.

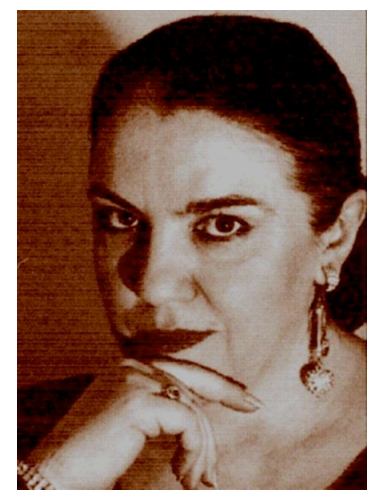

F 5. Elzbieta Towarnicka, la voz de Preisner

\section{4.- Análisis: la Trilogía Tres Colores (Trois couleurs)}

Analizaremos ahora la música de cada una de las tres partes de la Trilogía por separado, desarrollando más extensamente la primera parte de la Trilogía, Trois couleurs: Bleu, ya que en ella la música tiene un muy particular protagonismo.

\section{1.- Tres colores: Azul (Trois couleurs: Bleu, Krzysztof} Kieslowski, 1993)

Como ya se ha explicado, Trois couleurs: Bleu corresponde a la libertad. La trama se centra en la vida de Julie, la mujer de un reconocido compositor polaco, Patrice de Curcy. A raíz de la muerte de éste y de su hija en un accidente automovilístico, Julie ha visto su vida desmoronarse. Necesita liberarse del pasado para poder seguir viviendo y la película observa su particular proceso para conseguirlo, en un principio desprendiéndose de todo tipo de ataduras materiales y emocionales anteriores, posteriormente abriéndose de nuevo poco a poco al mundo a través de la composición musical. 


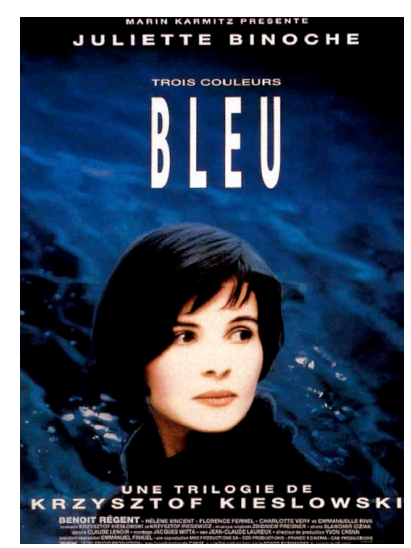

F 6. Cartel publicitario de Trois Couleurs: Bleu

La música de Trois couleurs: Bleu juega un papel extremadamente importante, al tratarse, en palabras de Preisner, de un musical: “(...) It is a musical, not, of course, in the Hollywood sense. It talks about a composer who composes for the sake of uniting Europe" (Paulus, 1999). Efectivamente, la música no sólo representa los sentimientos encontrados de Julie y su evolución a lo largo de la película, sino que también muestra paralelamente el proceso de composición musical que ella lleva a cabo con la obra que su marido dejara incompleta. Toda la película ilustra el proceso compositivo, con temas que se van repitiendo, variados, inacabados, esperando ser concluidos por los personajes de la historia y por el mismo espectador. Todos estos temas confluirán al final de la película en el Concierto para la Unificación de Europa. La música se convierte en esta película en un elemento cinematográfico esencial: el espectador, al que se invita a participar en el proceso compositivo, puede oír la música, verla representada en partituras e incluso imaginarla como otro personaje más.

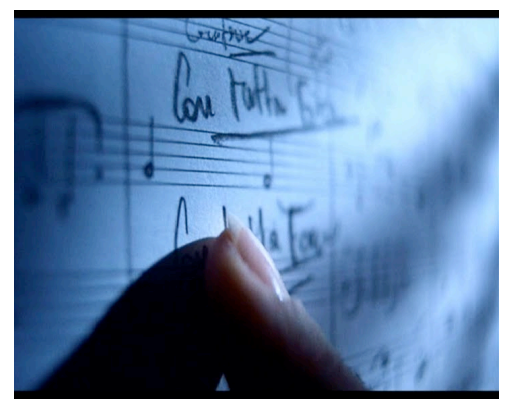

F 7. Fragmento de partitura original de Zbigniew Preisner que aparece en Trois couleurs: Bleu 
En Trois couleurs: Bleu, la música determina una atmósfera trágica y profunda, como la propia trama de la película. Por esta razón Preisner no sólo se sirve de la identidad musical de Van de Budenmayer para componer la mayor parte de la banda sonora, sino que también se menciona al artista holandés como personaje real al que Patrice de Curcy (personaje que encarna el compositor fallecido) admiraba profundamente.

Kieslowski ya había planificado de antemano cuidadosamente en qué momento exacto del metraje quería música y cuánto debía durar. Teniendo en cuenta esto, resultaría muy interesante realizar un análisis exhaustivo de la frecuencia de las intervenciones musicales y la duración de cada una de ellas en la película, ya que descubrimos que cada momento musical coincide con un acontecimiento importante del guión. No podemos profundizar en el desarrollo de esta idea, pero sí señalaremos algunas conclusiones importantes derivadas de este análisis: por ejemplo, no aparece una sola nota musical hasta el minuto ocho (exactamente, 8'29") de metraje, ni siquiera durante los títulos de crédito. No hay música, por tanto, durante el accidente automovilístico ni durante la convalecencia e intento de suicidio de Julie en el hospital, lo que inevitablemente confiere un gran realismo y crudeza a estas escenas.

Este silencio resulta inusual en una película que es considerada musical por su compositor, y consecuentemente va a provocar que la primera aparición musical genere una gran curiosidad y sorpresa por parte del espectador. El primer tema que aparece es la música del funeral del compositor Patrice de Curcy (Marcha fúnebre), que Julie ve a través de una pequeña pantalla de vídeo desde el hospital.

\section{Dos temas que definen a la protagonista}

Los dos primeros temas musicales que aparecen en la película, definidos muy acertadamente por Irena Paulus en su artículo (1999) como Marcha fúnebre y Tema de Julie, tienen en común el estilo inconfundible de Van den Budenmayer (música excepcionalmente melódica, construida a menudo sobre grandes intervalos) y el carácter fúnebre vinculado al motivo rítmico de 
corchea con puntillo y semicorchea. De hecho, ambos resultan absolutamente complementarios desde un punto de vista tonal, rítmico, melódico y tímbrico.

La Marcha fúnebre aparece en el minuto ocho (exactamente 8'29") de metraje y volverá a aparecer intermitentemente a lo largo de la película acompañada por un fundido en azul oscuro de la imagen, siempre que Julie rememora acontecimientos relacionados con el trágico accidente.

El Tema de Julie aparece por vez primera interpretado al piano por ella misma en un trozo de papel pautado e interrumpido por ella también cerrando bruscamente la tapa del piano (13'30" de metraje). Esta forma de presentarnos el Tema de Julie nos lleva a pensar que probablemente fuera una de las últimas composiciones de su marido, o incluso de la propia Julie (en la película se insinúa que era Julie la que componía las obras que firmaba su marido, o al menos parte de ellas). Sólo al final de la película, descubrimos que es una creación del enigmático Van de Budenmayer, al que tanto admiraba el difunto compositor Patrice de Curcy. Este fragmento musical parece perseguir a la protagonista a lo largo de toda la película, como insistiendo en la idea de que la libertad que ella busca no está en desprenderse de todo el pasado, sino en enfrentarlo para poder así superarlo. Por ello, el hecho de que Julie acepte finalizar la obra que su marido dejara incompleta, conforma una perfecta metáfora de su evolución emocional.

Hemos visto cómo se complementaban musicalmente ambos temas musicales y el significado de cada uno de ellos. ¿Por qué este vínculo especial entre ambos y su estrecha relación con Julie? Resulta evidente que la Marcha fúnebre nos recuerda el accidente, la muerte, por tanto. Por el contrario, el Tema de Julie representa algo vivo, incompleto. Ambos temas describen pues a Julie, al conflicto interno que ella está viviendo. De hecho, los dos aparecen juntos, interrumpiéndose literalmente, en un momento concreto de la película (44’ de metraje), cuando Julie comienza a enfrentar el pasado, aunque el momento musical empieza y termina con la Marcha fúnebre, dando a entender que ella todavía no lo ha superado. Éste es un buen ejemplo de música que crea cine, ya que en este momento ningún otro 276 
elemento cinematográfico señala este importante matiz en Julie: este importante conflicto interno sólo lo percibimos a través de la música. Por otro lado, podríamos interpretar ambos temas como sustitutos de la voz o los gritos de desgarro de Julie, ya que es presentado como un personaje muy introspectivo a lo largo de toda la película.

Antes de concluir con el tratamiento de estos dos motivos musicales, es preciso añadir que el Tema de Julie acaba sobreponiéndose a la Marcha fúnebre, no sólo porque la Marcha fúnebre no se integre al final en el Concierto para la Unificación de Europa, sino porque, a medida que Julie va aceptando el pasado y responsabilizándose de su presente, la Marcha se va descargando progresivamente de la negatividad y hastío iniciales (59" y 71'11" de metraje) y deviene metafóricamente en un reto a superar para la protagonista (71'11" de metraje) cuando decide conocer a la que fue amante de su marido.

\section{El misterioso flautista callejero}

Son muy destacables en la trama las tres apariciones de un flautista callejero. En cualquier otra película ni siquiera nos detendríamos a pensar en ello, pero en una obra de Kieslowski nada se abandona al azar y todo elemento cinematográfico tiene una razón de ser. En este caso, podemos deducir que la presencia del flautista y su música representan un importante estímulo de apertura al mundo y aceptación del pasado por parte de Julie. En un principio, la protagonista no parece prestar demasiada atención al sonido de la flauta. En la segunda aparición, Julie escucha mientras disfruta de los rayos del sol con los ojos cerrados. En la tercera aparición escucha atentamente y descubre que son fragmentos incompletos de algo que ella conoce (el Tema de Julie).

¿Por qué el flautista representa un estímulo para ella? Probablemente no sólo por las melodías incompletas que ella reconoce, sino también por el comportamiento de este hombre misterioso. El flautista toca en la calle, pero lo vemos salir de un coche acompañado por una mujer aparentemente de muy buena posición. Cuando Julie le pregunta por el origen de las melodías 
que interpreta, él responde que las inventa, que disfruta tocando. Es muy posible que esta actitud influya considerablemente en el nuevo despertar del amor por la música y por la composición en Julie

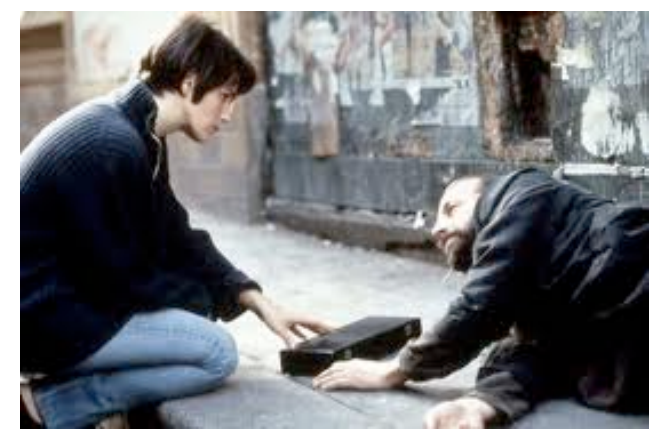

F 8. Julie hablando con el flautista

\section{Fragmento para un gran coro}

Hay otro tema que Patrice de Curcy dejó escrito antes de fallecer, aunque tal vez fuera compuesto por Julie. Es un breve fragmento para un gran coro que aparece al principio de la película, cuando Julie va a ver a la archivera de su marido y se lo pide para romperlo, una muestra más de su desesperado intento por olvidar el pasado. En esta ocasión oímos que dicha composición queda sin acabar, como si alguien lo hubiera interrumpido abruptamente (vemos que Julie lo destruye arrojándolo a una trituradora). Después, al final de la película, descubrimos que Olivier, colaborador de Patrice de Curcy, ya había hecho una copia del fragmento, previendo la reacción de Julie. Estos mismos coros vuelven a aparecer al final de la película, ya completos, integrados en el Concierto para la Unificación de Europa que componen juntos Julie y Olivier.

\section{El tema de Olivier ilustra el proceso compositivo}

Una vez que Julie accede a terminar de componer esta obra (metáfora de su aceptación del pasado) con Olivier, antiguo colaborador de Patrice, aparece un nuevo motivo musical: el Tema de Olivier. A este personaje se atribuye su composición, aunque él se basara en el estilo de su compañero Patrice de Curcy y, por tanto, también en el de Julie e, indirectamente, en el de Van den Budenmayer. El tema lo escuchamos primero sólo al piano (68'41" de metraje) y más tarde orquestado (78' de metraje). Esta nueva composición se 
incluye casi al final de la película en una escena que tiene como objeto mostrar verdaderamente la capacidad de Julie como compositora, quien corrige, variando la orquestación, el tema que ha escrito Olivier. Es un fragmento de una singular belleza y profundidad, sin duda uno de los más personales de Preisner.

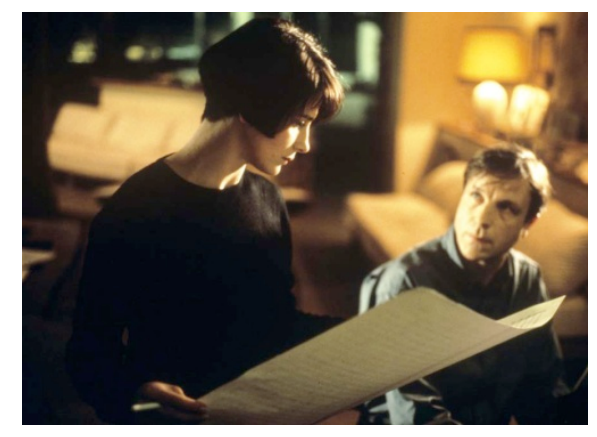

F 9. Julie y Olivier trabajando en la obra que de Curcy dejara incompleta

\section{Resultado final: Concierto para la Unificación de Europa}

El Concierto para la Unificación de Europa, según se explica en la propia película, se lo había encargado el Consejo de Europa a Patrice para que fuera interpretado por doce grandes orquestas sinfónicas de doce países de la Unión Europea. Tenía que ser algo grandioso y el fragmento de los coros ya ilustra muy bien el estilo que buscaba Patrice de Curcy. Su texto, en lengua griega, está extraído de la primera Epístola a los Corintios, que habla del amor como el único y más grande significado de la vida que, en el caso de Julie, es amor por la música.

Suponemos que escuchamos sólo un fragmento del Concierto para la unificación de Europa al final de la película, teniendo en cuenta su corta duración, pero sabemos que ya está terminado y podemos reconocer claramente algunos de los temas que hemos analizado y que han ido apareciendo a lo largo de la película. El fragmento que se nos presenta comienza con la parte de los coros y finaliza con el Tema de Julie, esta vez cantado también por un gran coro, que expresa un intenso himno final a la vida. 
4.2.- Tres colores: Blanco (Trois couleurs: Blanc, Krzysztof Kieslowski, 1994)

Trois couleurs: Blanc corresponde a la igualdad. En este film, Karol, un peluquero polaco que trabaja en Francia, está casado con Dominique, una bella francesa que inicia los trámites de divorcio debido a la incapacidad de Karol para consumar el matrimonio. En este doloroso proceso Karol lo perderá todo excepto su obsesión por Dominique. Forzado a volver a Polonia, luchará por construir una nueva vida a la vez que comienza a planificar una estrategia para vengarse de su antigua esposa. Esta relación de pareja es una metáfora que le sirve a Kieslowski para reflexionar sobre las difíciles relaciones entre Francia y Polonia.

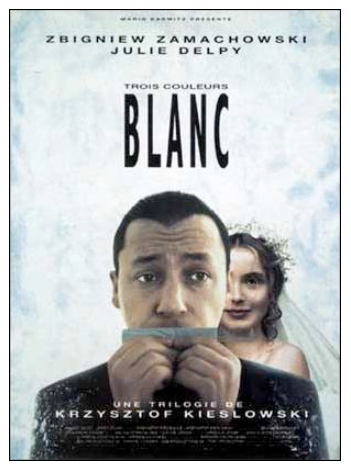

F 10. Cartel publicitario de Trois Couleurs : Blanc

La música de Trois couleurs: Blanc es más sencilla y menos trascendental que la de Trois couleurs: Bleu. Cuando Preisner la compuso estaba ya en la fase de montaje, por lo que podría presuponerse que la música podía resultar más anodina, menos trabajada. Nosotros consideramos que, teniendo en cuenta que la trama musical y compositiva no es el centro de la película, simplemente la música resulta menos compleja que la de Trois couleurs: Bleu, aunque en absoluto de inferior calidad. En esta composición reconocemos claramente la faceta más austera de Preisner.

Dos temas contrapuestos subrayan con ironía el misterio y la crueldad del asunto de las relaciones entre Francia y Polonia, reflejadas en los personajes de Dominique y Karol. Los dos motivos musicales se convierten en sendos leitmotivs para los dos protagonistas: ya desde los títulos iniciales, unas desangeladas notas de clarinete acompañan el recorrido de una maleta 280 
solitaria en la cinta de un aeropuerto, anticipando al espectador la huida de Karol a Polonia motivada por los trámites de divorcio de Dominique. Muy pronto se va a establecer el vínculo entre un sencillo y misterioso tema de clarinete y Francia (personaje de Dominique) y la relación entre un tango de gran influencia eslava, orquestado por cuerdas, con Polonia (personaje de Karol), que oímos por vez primera cuando Karol llega a Polonia. Este tango, aunque no se dice explícitamente, podría ser atribuible a Van den Budenmayer, ya que es la música que está sonando cuando se habla del compositor en una escena de Trois couleurs: Rouge (52'20” de metraje).

Por otra parte, también nos resulta muy interesante destacar un guiño de Zbigniew Preisner al compositor italiano Nino Rota: el tema que Preisner titula "Don Karol" en la banda sonora de Trois couleurs: Blanc ya nos proporciona una importante pista, y suena por vez primera cuando el protagonista Karol consigue hacerse un hueco en el mundo de los negocios en Polonia. Su ritmo ternario y sus giros melódicos recuerdan en buena medida al que compusiera Nino Rota para El Padrino (The Godfather, Francis Ford Coppola, 1972).

\section{3.- Tres colores: Rojo (Trois couleurs: Rouge, Krzysztof Kieslowski, 1994)}

Finalmente, Trois couleurs: Rouge corresponde a la fraternidad. Valentine es una joven estudiante francesa que se gana la vida como modelo. Una noche atropella accidentalmente a una perra y, tras curarla de sus heridas, busca a su dueño para devolvérsela. La búsqueda le conducirá hasta un juez jubilado y solitario que ocupa su tiempo en espiar a sus vecinos. En un principio, la posición idealista ante la vida de la joven chocará frontalmente con el cinismo del desilusionado anciano, aunque poco a poco irá creciendo entre ellos una sólida amistad. 


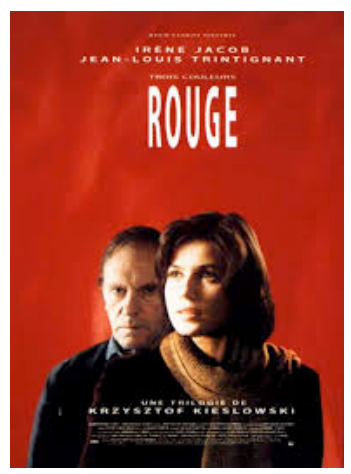

F 11. Cartel publicitario de Trois Couleurs : Rouge

La trama de Trois couleurs: Rouge probablemente sea la más metafísica y compleja de toda la Trilogía. Y no nos referimos únicamente a su contenido: el film adquiere un carácter testamentario al ser el último que rodó el realizador polaco, fallecido en 1996. No es objetivo de este trabajo analizar en profundidad esta difícil obra pero sí vamos a hacer a continuación algunas consideraciones sobre la música de la misma.

La banda sonora de esta película resulta, al igual que en Trois couleurs: Blanc, más sencilla de analizar que la de Trois couleurs: Bleu, ya que la música tampoco aquí es el objeto mismo de la película. Sin embargo, ésta resulta fundamental para comprender mejor la compleja trama de la historia. En esta ocasión, Preisner se sirve exclusivamente de dos temas musicales que constituyen una de sus bandas sonoras más conseguidas, y por la que, además, recibió un Premio de la Academia de Cine Francesa en 1995.

\section{Bolero}

El tema principal es un bolero. En palabras del compositor: “(...) el bolero guarda correspondencia con el espíritu de la película: un tema que se desarrolla y va repitiéndose. El bolero puede aportar mucha energía, acelerar la acción. También le proporcionará un aspecto inquietante.” (Montalt, 2003).

Efectivamente, este bolero pauta la evolución de la relación que se establece entre el juez y Valentine a través de sus diferentes encuentros, que les van uniendo cada vez más estrechamente. La primera vez que aparece es en el minuto seis de metraje (6'34"exactamente), en un desfile de modelos en el 
que participa Valentine, hecho que anticipa su inminente encuentro con el juez y su última y reveladora conversación tras otro desfile de la protagonista. Por otra parte, cabe destacar que ésta es la primera intervención musical de toda la película, subrayando así la importancia de este tema y el momento de la trama en el que se produce.

La tonalidad principal de este tema es un abierto y feliz Re mayor, como la propia relación que mantienen el juez y Valentine, aunque ciertos giros melódicos basados en la escala de Re menor armónica, le proporcionen importantes dosis de misterio e inquietud, dos sentimientos que rodean asimismo la relación de ambos personajes. Por otra parte, en este tema Preisner sabe conjugar muy bien la inexorable ansiedad que provoca un bolero con el lirismo que consigue al final del mismo, con coros que culminan finalmente en $\operatorname{Re}$ mayor, como un toque de esperanza y humanidad (fraternidad) que afecta a toda la Trilogía y que podría interpretarse como el último mensaje del cineasta.

Hemos destacado que el tema del bolero tiene una parte central misteriosa, desasosegante, además de la inquietud propia de esta peculiar forma musical. Como ya hemos ido analizando, ni Kieslowski ni Preisner dejan ningún detalle al azar, y esto, por supuesto, no es ni mucho menos casual. De hecho, es un detalle importante para la trama: este siniestro fragmento para cello en Re menor recuerda que, a pesar de la buena y abierta relación entre Valentine y el juez, hay importantes confidencias que todavía no se han intercambiado y que no se revelarán hasta su última conversación en el foso del teatro, tras el desfile de modelos de Valentine.

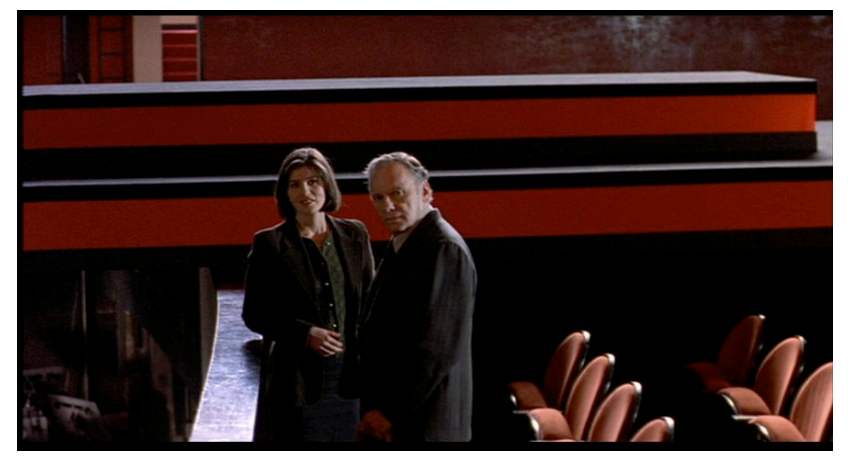

F 12. Última conversación entre Valentine y el juez

283 


\section{La magia de Budenmayer}

La segunda propuesta musical de Trois couleurs: Rouge no guarda ningún tipo de relación musical con el bolero. Por supuesto, Preisner sigue siendo su compositor, pero esta vez se convierte en Budenmayer. O más bien deberíamos decir que se convirtió en Budenmayer, ya que esta pieza no la escribió expresamente para esta película: procedía de la música que podía escucharse en la novena parte de Dekalog, la obra que realizara Kieslowski en 1988 relativa a los Diez Mandamientos. Resulta muy revelador comprobar que el tema principal de la película ligada al Noveno Mandamiento (No desearás a la mujer del prójimo), marcada por los celos e infidelidades en la pareja, aparezca en esta película, subrayando así los engaños que surgen también en Trois couleurs: Rouge y conectando ambas películas dentro de la obra, tanto de Kieslowski como de Preisner.

Dicha pieza la oímos por primera vez en el minuto cuarenta y cuatro de metraje (exactamente 44'15”), cuando, aparentemente, nada de lo sucedido hace presagiar ningún tipo de traición. Una vez más, la música se anticipa a la trama argumental; toma el carácter de una intuición, anticipándose a la confirmación de la realidad. Es en este momento en el que empezamos a seguir más de cerca un argumento paralelo al del viejo juez y Valentine, es decir, la relación entre Auguste (el juez joven a punto de licenciarse), y su pareja. Muy pronto descubriremos, también a través de la imagen, que la novia de Auguste le es infiel.

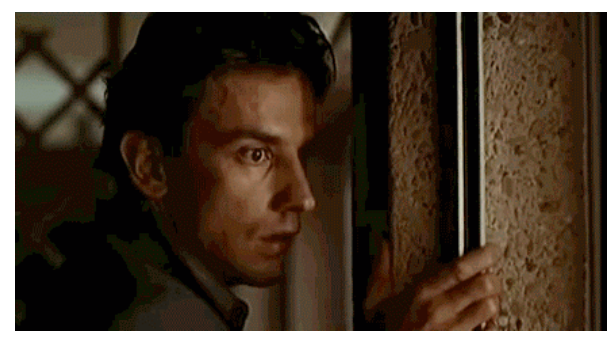

F 13. El joven Auguste descubre que su pareja le es infiel

Este mismo tema musical relaciona a Valentine y Auguste en una tienda de música, cuando Valentine quiere comprar un $\mathrm{CD}$ de Budenmayer del que Auguste acaba de llevarse el último ejemplar. Auguste, como una 
prolongación del viejo juez, se cruza con Valentine a lo largo de toda la película, pero no llegan a conocerse hasta el final ${ }^{2}$. Por otra parte, los acontecimientos que viven ambos jueces son muy similares, especialmente esa traición sentimental. Lo que diferencia a ambos es su final: el anciano juez fue traicionado y desde entonces se encerró en sí mismo; el joven Auguste también es traicionado, pero el destino le hace toparse por fin con Valentine. Podríamos decir que el juez no encontró a Valentine en su juventud y la encuentra ahora a través de Auguste.

Este segundo motivo musical hemos dicho que está compuesto por Van den Budemayer. No es una pieza ejemplar del estilo solemne que ya hemos descrito, sino más bien una canción para voz soprano y un sencillo acompañamiento instrumental. Es una pieza sobria, pero en ella subsisten una gran profundidad y misterio, que contrastan con la apertura general del bolero.

\section{4.- La Trilogía de los Tres Colores: un gran concierto}

La Trilogía entera está concebida como un gran concierto clásico desde todos los puntos de vista, no sólo musicalmente, y la cohesión entre cada una de las partes ya es un indicio de esta gran forma global.

Como ya hemos destacado, es muy importante la presencia de Budenmayer como nexo entre las partes. Por otro lado, también los propios personajes unen las tramas de las tres películas. En Trois couleurs: Bleu y Trois couleurs: Blanc, los protagonistas se cruzan en un juicio, y en Trois couleurs: Rouge aparecen los protagonistas de las tres partes al final del film. Por otra parte, hay un curioso personaje que también se muestra en cada una de las partes de la trilogía: se trata de una anciana que tiene dificultades para llegar a la boca de un contenedor y arrojar sus botellas de vidrio. $\mathrm{Al}$ respecto, es

\footnotetext{
${ }^{2}$ En este sentido, resulta muy interesante conocer la obra de la poetisa y ensayista polaca Wislawa Szymborska (Premio Nobel de Literatura en 1996), concretamente su poema Amor a primera vista (Fin y principio, 1993), cuyo contenido está relacionado precisamente con los juegos del azar antes de devenir en destino. Zbigniew Preisner puso música a este poema, del cual existe una versión en polaco y otra en francés. La pieza musical resultante forma parte de la banda sonora de Trois Couleurs: Rouge, aunque no se incluya después en la película.
} 
muy reveladora la evolución de la actitud de nuestros protagonistas a lo largo de la Trilogía: en Trois couleurs: Bleu, Julie está tomando el sol en el parque con los ojos cerrados y, por tanto, no es consciente de la presencia de la anciana. En Trois couleurs: Blanc, Karol, recién rechazado por su mujer, ve a la anciana pero no se acerca para ayudarla. Es en Trois couleurs: Rouge, cuando Valentine, finalmente, la ve y la ayuda a deshacerse de los vidrios. La anciana viene a ser un resumen de los tres ideales de la Revolución Francesa, en los que está basada cada una de las tres partes de la Trilogía, y, en función de la actitud que muestran, sirve para reflejar el estado emocional de los personajes en cada una de las películas. Por añadidura, este personaje de la anciana une La Trilogía al resto de la obra la obra de Kieslowski, ya que también está presente en otras de sus películas, como La double vie de Véronique (Krzysztof Kieslowski, 1991).

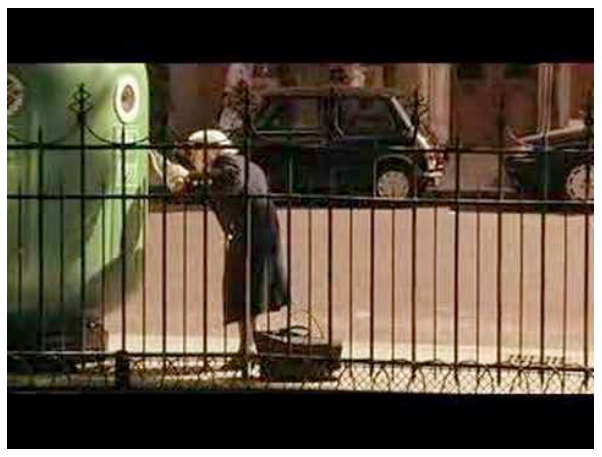

F 14. La anciana tratando de deshacerse de sus botellas de vidrio, leitmotiv de la Trilogía

Del mismo modo, las tres películas de la Trilogía terminan con el primer plano de uno de los protagonistas como resumen de todo la cinta. En Trois couleurs: Bleu es Julie la que aparece, libre ya de su dolor, en Trois couleurs: Blanc es el empresario Karol, que por fin ha conseguido sentirse en relación de igualdad con su mujer; y en Trois couleurs: Rouge, el viejo juez, que parece haber logrado el amor de Valentine a través del joven Auguste. No son pocos los críticos que han visto en el personaje del anciano juez a un demiurgo que maneja a los personajes de toda la Trilogía a su antojo, juntándolos y salvándolos a todos en el ferry que insta a coger a Valentine. Es decir, que el juez podría considerarse, en cierto modo, el propio Kieslowski. 


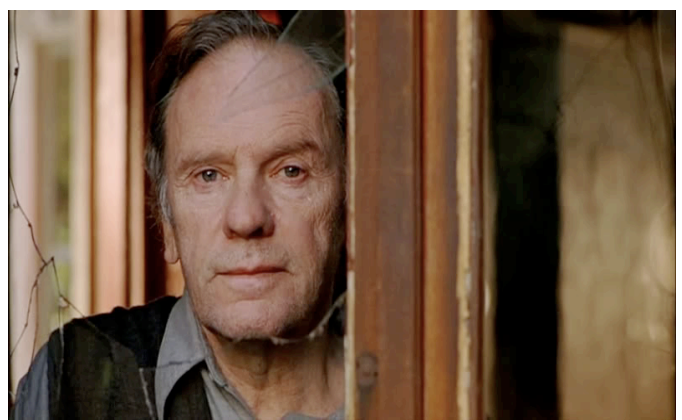

F 15. El juez (Jean-Louis Trintignant), álter ego del propio Kieslowski, en el último plano de Trois Couleurs: Rouge

Un fuerte elemento de cohesión es también la estupenda fotografía, que subraya en todo momento el color dominante en cada parte y su relación con el ideal francés correspondiente: el misterio y la introversión del azul, la neutralidad y estatismo del blanco y la calidez y extraversión del rojo.

Por otra parte, en un concierto clásico encontramos tres movimientos, de los cuales el primero suele ser siempre el de más peso, el segundo es más ligero, con un ritmo más pausado, y el tercero equilibra el conjunto, más cercano en intensidad a un primer movimiento, pero normalmente con un carácter más desenfadado (A-B-A'). El vínculo entre el primer y tercer movimiento lo encontramos ya en el hecho de que las protagonistas de Trois couleurs: Bleu y Trois couleurs: Rouge sean femeninas, mientras que en Trois couleurs: Blanc, el protagonista es masculino.

Este reparto de intensidad, a modo de un concierto clásico, por supuesto se ve subrayado por la trama argumental que, como ya hemos visto, en la Trilogía se encuentra estrechamente vinculada a la música. Así, la música de Trois couleurs: Bleu posee la fuerza típica de un primer movimiento de concierto clásico, mientras que la de Trois couleurs: Blanc es más sencilla y equivalente a un segundo movimiento de concierto, descargando buena parte de la tensión acumulada. En la música de Trois couleurs: Rouge el bolero es un tema fundamental, de carácter repetitivo y que deja una sensación similar a la del estribillo que va alternándose con coplas en un rondó, típica forma musical de tercer movimiento de concierto clásico. La música de Trois couleurs: Rouge es de menor fuerza dramática que Trois couleurs: Bleu, pero es mayor que la de Trois couleurs: Blanc, volviendo al tono más 
trascendental y profundo de la primera parte para concluir y cerrar la Trilogía.

\section{5.- Conclusión}

Probablemente, para llegar a resultados como el de la obra que aquí se ha tratado, es importante el punto de vista tanto del realizador como del compositor sobre la esencia y finalidad del trabajo artístico. En función de la óptica sobre la creación propia, ancilar o de protagonismo, el trabajo en colaboración mostrará realizaciones artísticas separadas entre sí o integradas en estrecha comunión, aprovechando cada expresión artística las sinergias de la otra. Y, al mismo tiempo, consiguiendo un gran grado de autonomía y belleza cuando las analizamos separadamente.

Sin duda, la Trilogía de los Tres Colores, constituye una de las grandes obras maestras del séptimo arte del último tercio del siglo XX. En la historia del cine, aunque existen muchos ejemplos de bandas sonoras de gran calidad, son pocas las películas en las que realizador y compositor hayan trabajado tan estrechamente, otorgando a la música una importancia y protagonismo tan evidente en la experiencia audiovisual resultante. Otros autores, como la profesora Irena Paulus, coinciden con nosotros:

"In Three Colors: Blue every moment, in every part (pictorial, photographic, musical, setting, acting, technical and so on) has been very carefully thought through, planned in advance and worked out in the mind. Behind it all there is an amazing and unique manner of thinking that offers an ineffable aesthetic and artistic pleasure. It is a pity that the artist has gone for ever and that we will not have the opportunity to see more of his work. Kieslowski's works sharpen the artistic appetite to the point of insatiability, and it can be slaked only by the knowledge that there will be no more of it, that it is the only one of its kind. Perhaps it is better this way, for one is valued higher than many. His films and the lovely music of Zbigniew Preisner, which he himself admired so much, are all that remain (...)" (Paulus, 1999, 90) 
Ahora bien, más allá de estas consideraciones, tras la audición completa de la música que compusiera Preisner para la Trilogía en su correspondiente grabación discográfica, bien podríamos colegir que, por sí misma, ya forma un universo peculiar, con independencia y valía artística ciertamente indiscutibles. En este sentido, discrepamos claramente de algunas de las observaciones de la profesora Irena Paulus, quien cuestiona la calidad de la obra de Preisner aislada de su contexto cinematográfico:

“(...) An attempt to listen Preisner's music from some recording (and you can try it yourself) is a failure; the music is disappointingly Split up and is hard to enjoy it..." “(...) listened on their own (the sentences) are just incomplete fragments without point or inner beauty." “(...) the music, separated from the film, means nothing, while the environment for which it was created it is full of symbolism, meaning, point and function.” (Paulus, 1999)

Lamentablemente, también son muchos los críticos cinematográficos que han visto en la Trilogía únicamente una magnífica producción cinematográfica, sin reparar suficientemente en el increíble poder, calidad y protagonismo que tiene su música. Por ello, esperamos que este artículo pueda contribuir a suscitar un mayor interés por la obra del compositor Zbigniew Preisner, todavía, creemos, demasiado desconocido en nuestro país ${ }^{3}$.

\section{Referencias bibliográficas}

Chion, M. (1992). El cine y sus oficios. Madrid: Cátedra.

Chion, M. (1997). La música en el cine. Barcelona: Paidós.

Darke, Ch., Preisner, Z. (1996). "Working with Kieslowski + An interview with Zbigniew Preisner, composer”. En: Sight and Sound, 6, V (1996), pp. 20-20.

Lack, R. (1999). La música en el cine. Madrid: Cátedra.

Montalt, S. (2003). Krzysztof Kieslowski. Tres colores: Rojo. Estudio crítico de Salvador Montalt. Barcelona: Paidós.

3 En este sentido, nos referimos a la escasa investigación sobre la música del compositor polaco existente en España: las búsquedas en las principales bases de datos en castellano apenas dan resultados. 
Paulus, I. (1999). "Music in Krzysztof Kieslowski’s film “Three Colors Blue”. A rhapsody in shades of blue: The reflections of a musician". En: International review of the aesthetics and sociology of music, 30, I (1999), pp 65-91.

Xalabarder, C. (1997). Enciclopedia de las Bandas Sonoras. El estudio más completo de la música de cine desde los orígenes hasta la actualidad. Barcelona: Ediciones B.

Fimaffinity, < http://www.filmaffinity.com/es/> (julio 2012).

Johnson, Edward, "Bernard Herrmann - A Biographical Sketck" <http://www.bernardherrmann.org/articles/biographical-sketch/> (junio 2012- septiembre 2013).

Ponti, Edoardo, "Interview with Zbigniew Preisner", <http://www.musicolog.com/preisner_interview.asp > (febrero-marzo 2012).

Preisner, Zbigniew, <www.preisner.com> (julio 2011-junio 2012).

Rosebud Tienda de Cine, <www.arrakis.es/ saimel/PREISNER.HTM> (febrero 2012).

\section{Referencias filmográficas}

Dekalog (Krzysztof Kieslowski, 1988)

La doble vida de Verónica (La double vie de Véronique, Krzysztof Kieslowski, 1991)

Tres Colores: Azul (Trois couleurs: Bleu, Krzysztof Kieslowski, 1993)

Tres Colores: Blanco (Trois couleurs: Blanc, Krzysztof Kieslowski, 1994)

Tres Colores: Rojo (Trois couleurs: Rouge, Krzysztof Kieslowski, 1994) 